\title{
O USO DA MADEIRA NAS REDUÇÕES JESUÍTICO-GUARANI DO RIO GRANDE DO SUL \\ 4 - VERGA DA PORTA DA SACRISTIA NOVA (LADO EVANGELHO) DA IGREJA DE SÃO MIGUEL ARCANJO ${ }^{1}$
}

\author{
MARIACRISTINA SCHULZE-HOFER ${ }^{2}$ JOSÉ NEWTON CARDOSO MARCHIORI $^{3}$
}

\begin{abstract}
RESUMO
A madeira da verga da porta da sacristia nova (lado evangelho) da Igreja de São Miguel Arcanjo foi anatomicamente identificada como ipê-roxo, Tabebuia heptaphylla (Vell.) Toledo, espécie lenhosa de notável resistência físico-mecânica e alta durabilidade natural.

Palavras-chave: Tabebuia heptaphylla, Anatomia da madeira, Missões Jesuíticas.
\end{abstract}

\section{SUMMARY}

[Wood utilization in the Jesuitic-Guarani Missions from Rio Grande do Sul state, Brazil. 4 - New sacristy lintel of Saint Michel Archangel Church].

The lintel wood of Saint Michel Archangel's new sacristy was anatomically identified as Tabebuia heptaphylla (Vell.) Toledo, the regional "ipê-roxo", a species of wood notable for its strength and decay resistance.

Key words: Tabebuia heptaphylla, Wood anatomy, Jesuitic Missions.

\section{INTRODUÇÃO}

Sem identificação botânica, até momento, a madeira da verga da sacristia nova (lado evangelho) da Igreja de São Miguel Arcanjo é o objeto da presente pesquisa anatômica, que visa a contribuir para o conhecimento sobre o uso deste recurso natural renovável nas antigas Missões Jesuítico-Guarani do Rio Grande do Sul.

\section{MATERIAL E MÉTODOS}

O material em estudo consiste de uma amostra de madeira (Figura 1A,B) retirada da verga da sacristia nova (lado evangelho) da Igreja de São Miguel Arcanjo, em junho de 2005. Sem

${ }^{1}$ Recebido em 10-8-2007 e aceito para publicação em 309-2008.

2 Arquiteta, Dra. IPHAN - Instituto do Patrimônio Histórico e Artístico Nacional. schulze-hofer@gmx.de

3 Engenheiro Florestal, Dr., bolsista de Produtividade em Pesquisa do CNPq, Professor Titular do Departamento de Ciências Florestais, Universidade Federal de Santa Maria,RS.balduinia@mail.ufsm.br sinais aparentes de biodeterioração, o material foi registrado em fichário, fotografado, acondicionado em envelope com identificação e enviado ao Laboratório de Anatomia da Madeira do Instituto Nacional de Pesquisas da Madeira, em Lohbrügge (Alemanha), onde foram realizados os trabalhos de microtécnica e fotomicrografia.

$\mathrm{Da}$ amostra de madeira foram preparados corpos-de-prova, orientados para a obtenção de cortes anatômicos nos planos transversal, longitudinal radial e longitudinal tangencial. Os corpos-de-prova foram amolecidos por fervura em água e seccionados em micrótomo de deslizamento, modelo American Optical, regulado para a obtenção de cortes com espessura nominal de $20 \mu \mathrm{m}$. Tendo em vista a boa conservação do tecido lenhoso, não foi necessário incluir os corpos-de-prova em polietilenoglicol. Os cortes anatômicos também não foram coloridos; no caso dos radiais, parte deles foi tratado com hipoclorito de sódio, com vistas a salientar a eventual presença de cristais de sílica e oxalato 

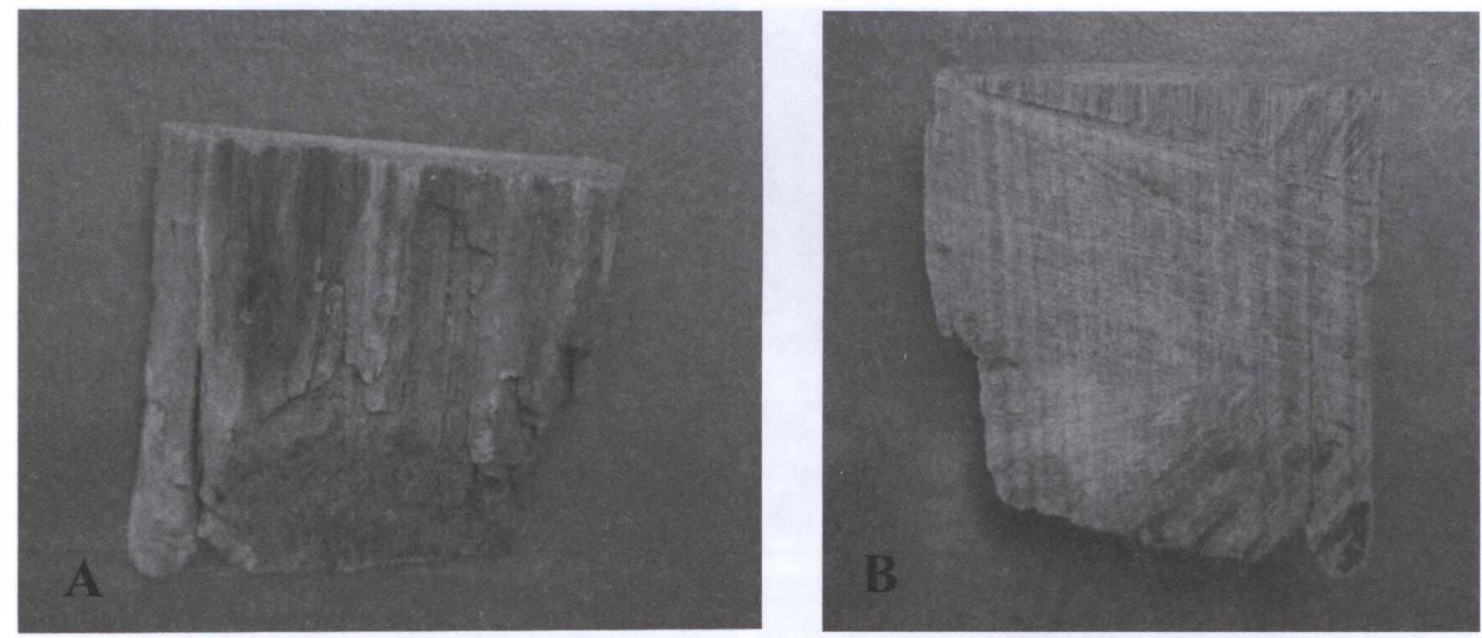

FIGURA 1 - Duas vistas (frente e verso) da amostra de madeira da verga da porta da sacristia nova da Igreja de São Miguel Arcanjo.

de cálcio. As fotomicrografias da Figura 2 foram tomadas com câmera Olympus AX, com diferentes aumentos.

\section{DESCRIÇÃO ANATÔMICA}

Anéis de crescimento distintos (Figura 2A). Porosidade difusa (Figura 2A). Poros muito numerosos, arredondados ou ovais, solitários, geminados (Figura 2A,B) e em múltiplos radiais de 2-3, raro 4 unidades. Madeira de estratificação completa, incluindo elementos vasculares, parênquima axial, raios e fibras (Figura $2 \mathrm{E}, \mathrm{F}$ ).

Elementos vasculares retilíneos (Figura 2CF), com placas de perfuração simples e abundante conteúdo nos vasos. Pontoações intervasculares alternas, não ornamentadas, de 12 a $14 \mu \mathrm{m}$ de diâmetro, com aréola circular e abertura lenticular inclusa. Espessamentos espiralados, ausentes.

Parênquima vasicêntrico incompleto, tendente a confluente, sem formar, todavia, faixas concêntricas (Figura 2A, B). Séries parenquimáticas geralmente com duas células por série.

Raios homogêneos, com frequiência de 5-10/ $\mathrm{mm}$ (Figura 2E), compostos inteiramente de células procumbentes (Figura 2D). Raios com menos de 10 células de altura e geralmente trisseriados, menos comumente uni e multisseriados (Figura 2E, F).

Fibras libriformes, de paredes espessas a muito espessas (Figura 2B).

\section{ANÁLISE DA ESTRUTURA ANATÔMICA}

Os detalhes anatômicos permitem uma fácil identificação da madeira. A família Bignoniaceae é facilmente reconhecida, em chave dicotômica para madeiras de estrutura estratificada (Record, 1943), pelas pontoações não ornamentadas, pelos raios relativamente estreitos e baixos, pela porosidade difusa e pelos vasos desprovidos de espessamentos espiralados.

$\mathrm{Na}$ chave para os grupos genéricos dessa família, conclui-se que o material em estudo pertence ao "grupo Lapacho" do gênero Tabebuia (Record \& Hess, 1940), devido à porosidade difusa, aos raios com 3-4 (raro mais) células de largura e menos de 10 células de altura, ao parênquima escassamente vasicêntrico, aliforme até confluente, e à abundância de conteúdo amarelado nos vasos.

Com numerosas espécies e ampla distribuição geográfica, o "grupo Lapacho" distinguese das demais seções de Tabebuia pela madei- 

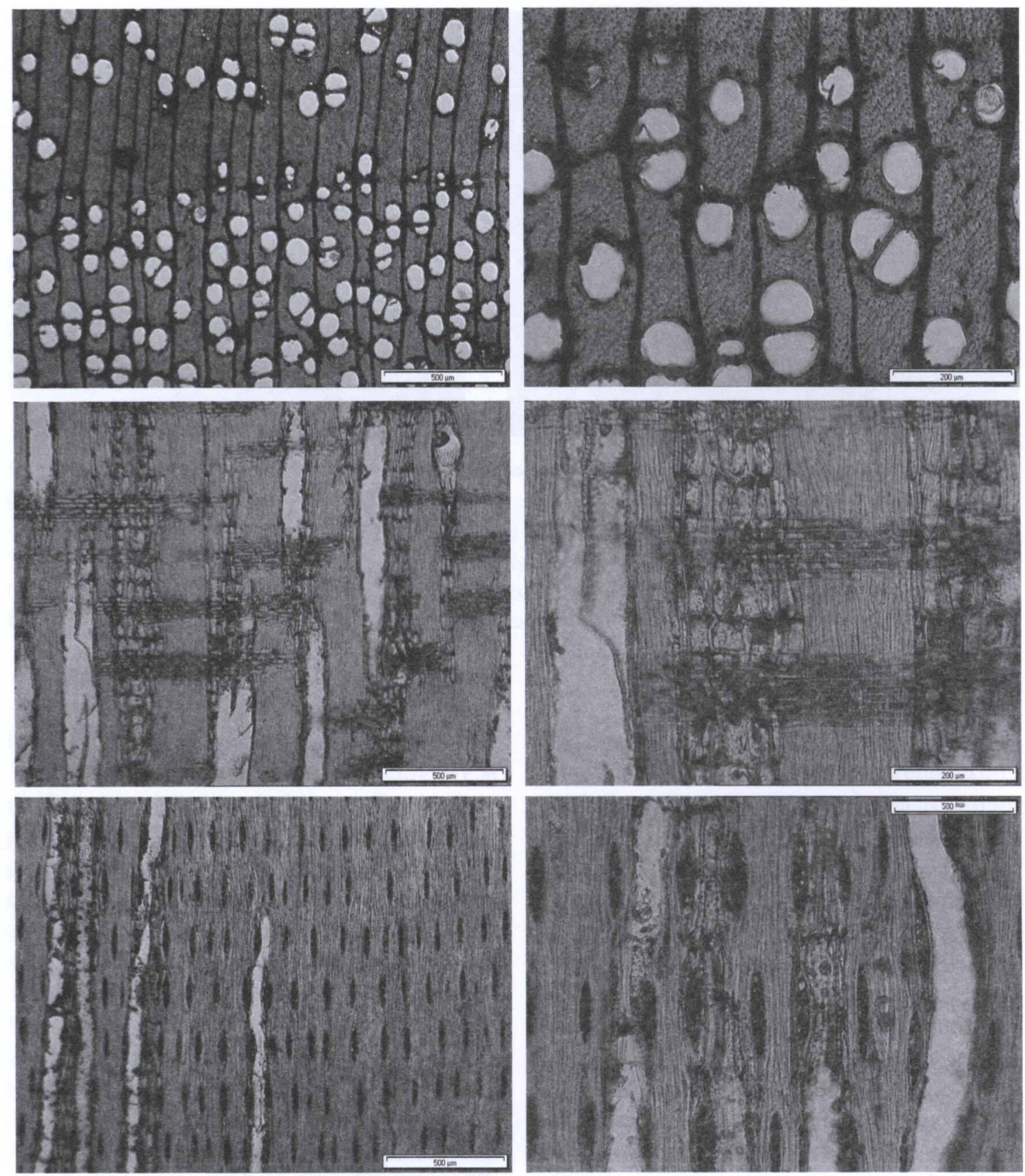

FIGURA 2 - Fotomicrografias da madeira da verga da porta da sacristia nova (lado evangelho) da Igreja de São Miguel Arcanjo. A - Anel de crescimento distinto, poros muito numerosos, arredondados a ovais, parênquima paratraqueal escasso, pouco confluente, e fibras de paredes espessas a muito espessas, em seção transversal. B - Mesmos aspectos da imagem anterior, com maior aumento. C - Linhas vasculares retilíneas e raios homogêneos, em seção radial. D - Mesmos aspectos da imagem anterior, com maior aumento. E - Estratificação completa, linhas vasculares retilíneas e fibras de paredes muito espessas, em seção tangencial. F - Mesmos aspectos da imagem anterior, com maior aumento. 
ra castanho-esverdeada de alta densidade e pela presença de abundantes depósitos amarelados (lapachol) nos vasos do cerne (Record \& Hess, 1943). Por todos estes aspectos, não restam dúvidas sobre a inclusão do material em estudo no referido grupo infragenérico.

Por fim, o exame comparativo com espécies do referido grupo, representadas no laminário do Departamento de Ciências Florestais da UFSM, leva à conclusão de que o material corresponde a Tabebuia heptaphylla (Vell.)
Toledo, devido aos raios relativamente finos e escasso parênquima axial.

LITERATURACITADA

RECORD, S.J. Woods of storied structure. Tropical Woods, n. 76, p. 32-47, 1943.

RECORD, S. J., HESS, R. W. American timbers of the family Bignoniaceae. Tropical Woods, n. 63, p. 938,1940 .

RECORD, S. J., HESS, R. W. Timbers of the New World. New Haven: Yale University Press, 1943. 640 p. 